\title{
Tutoring as a Way of Organizing University Space for the Academic Qualification of Young Researchers: the Russian Context
}

\author{
Elena A. Gavrilina ${ }^{*}$ \\ ${ }^{1}$ Bauman Moscow State Technical University, 2nd Baumanskaya str., 5/1, 105005, Moscow, Russia
}

\begin{abstract}
The article deals with the study of the tutoring phenomenon in the past and in modern times. The relation between tutoring and the development of metacompetitions of tutorantshas been traced. The concepts of meta-subject matter, metacognitiveness and metacreativity are specified in the educational context. The neccesityto include tutoring in the modern Russian education, especially to the scientific training of students, has been shown.

The need for inclusion of tutoring in the space of modern Russian education is shown, especially concerning the scientific training of students.
\end{abstract}

\section{Introduction}

The modern educational system soon will have some significant changes. Technical and scientific progress, the globalization of the economy, politics, social and cultural processes and institutions leads to the complication and diversification of status-role, including professional positions, forming new requirements for the qualities and competencies of each person. This necessarily requires an increase in individualization in the higher education, which is also confirmed by the national educational strategy reflected in the Education Quality Management Concept of the Ministry of Education and Science and in the Law of the Russian Federation "On Education".

Hence, it seems necessary to study the pedagogical experience of individualiz-ing educational strategies, from which tutoring is the most influential.

\section{The concept of tutoring}

The application of tutoring to the educational system, its use as a project idea, suitable for reforming the education system requires clarification of the concept itself, based on its various interpretations.

The Oxford Dictionary gives two basic meanings of the word "tutor":

- a private teacher working individually or in a very small group of stu-dents;

\footnotetext{
* Corresponding author:gavrilina@bmstu.ru
} 
- a teacher who is responsible for a small group of students at a school, college, or university. The tutor advises students regarding the organi-zation of their studies or helps them if they have any problems [1].

The first value reflects the equivalence of the concept of "tutor" to the Rus-sian concept of "coach" and is not of interest in the context of our study. Therefore, we will focus on the second meaning as a basic concept of "tutor", and we will use the concept of "tutor" in the text in this meaning. Also, it is obvious that the second meaning of tutoring is close in meaning to the Russian concept of "mentor" and we will use them as synonyms.

Researchers $[2,3]$ record two types of approaches to determining the problem situation in the modern education system, and, consequently, different in their orien-tation methods of interpretation, understanding the essence of the contradictions arising in educational practice, and hence the way to overcome them, including the ways with using tutoring.

In the first approach, the tutorial position serves to strengthen the pedagogical position the teacher's position, which helps to eliminate or compensate such un-wanted "disturbances" in the process of normal reproduction, such as student's mis-understanding, his physiological and psychological features, the nature of the social environment, personal history, etc. The problems that exist in the educational sphere are associated with inconsistencies within the traditionally established processes of reproduction. Therefore, as a rule, the tutor's activity in this logic takes shape in an orientation toward a compensatory function, focusing on problems of academic performance, discipline, adequate leisure, and so on. Here the idea of an individual approach arises as a means of overcoming the "discrepancy between the level of educational activity, which is set by the programs, and the student's real abilities to master them".

The second approach combines courses that consider the principle of repro-duction as a problem. The main critical pathos of these courses is connected with the idea of an "anthropological catastrophe" as a result of the "dehumanization of edu-cation", the loss of the human dimension itself. It is noted that the main thing is not happening in education today - self-determination of a person, a person's choice of himself in the world of history and culture. And therefore, within the framework of this trend, all attempts to "take into account the students' individual characteristics" turn into a set of measures to rehabilitate what is not an individual in the proper sense of the word [4]. In this regard, education is called upon to cultivate a special tech-nique - the "test of strength" technique to establish "the proportionality of the order of the individual soul with the world around us, that is, with the fact that it is larger than the person itself" [5].

\subsection{Problems of the education system and tutoring}

People often talk about the "dehumanization" of education. So it would be erroneous to say that the prospects of tutoring and even considering it as a specific anthropo-practice aimed at subjectificationof all participants in the educational process can be built independently from discussing the principle of the reproductionidea, which is based on the heterogeneity idea of the world, named transcendental principle of European culture by M.K. Mamardashvili [6]. M.K. Mamardashvili notes that attempts constantly occurring in history to mythologize the transcendental foundations of culture and the formation of the natural science paradigm have led to the notion of learning, especially institutionalized learning, as conveying the general picture of the world. And in this sense, education is moving away from the ideal of "ascent to the Truth"and becomes a set of ideas and precepts that need to be memorized. However, among the many works on education, based on the anthropological ideal of a rational person, there are studies based on completely different grounds [7]. 
In this context, tutoring becomes a special type of social learning, involving a person in a culture of working with knowledge (particularly, scientific) both in the professional environment and in everyday life.

So, having designated the initial "framework", we will try to outline the historical reconstruction of tutoring.

\subsection{Historical aspects of tutoring [8]}

Tutoring as one of the institutionalized forms of mentoring arose in the first British universities - Oxford (XII century) and Cambridge (XIII century).

Unlike the German university model (borrowed, by the way, in Russia), which is based on the system of departments and the curriculum assigned to each department, the English university did not care about students taking particular courses. Each professor read and commented on his book. The student had to decide for himself which professors and what subjects he would listen to. The university, on the other hand, presented its requirements only on exams, and the student had to choose the path in which he would gain the knowledge necessary to obtain a degree.

Tutors were charged with overseeing a certain number of schoolchildren; they accompanied the student's life in college, including his daily life, prepared for academic lectures and led private classes.

By the end of the XVI century, the tutor became the central figure in university education, responsible primarily for the education of the advisee. In the XVII century, the sphere of activity of the tutor expands - educational functions begin to acquire increasing importance. The tutor advises the student which lectures and practical classes are best attended, how to plan academic work, makes sure that his students are well engaged and ready for university exams. The tutor is the student's closest councilor and assistant in all difficulties; in fact, the tutor replaces the student with the parents. In the XVII century, the tutor system is officially recognized as part of the English university system, gradually replacing the professors. During the XVIII-XIX centuries, at the oldest universities in England, the Tutor system did not give up its position but took a central place in education; the lecture part began to complement it. Today, approximately $90 \%$ of classes at Oxford and $75 \%$ at Cambridgeare taught for one or two students.

\subsection{The nature and structure of tutoring}

The traditional structure of the tutoring system includes three elements: class management (supervision), which provides students with studies and work during the holidays; moral mentoring, which involves co-leading the life of a student at a university in the broadest sense of the word; tutoring itself, which provides student training during the trimester or academic year.

Thus, the classical model of tutoring implies the establishment of personal guardianship of a specialist over a student. And the main goal of thetutoring classical model is the development of students' metacognitive abilities as subjects of education based on the principle of individualization.

Thus, it can be assumed that the idea of the development of human thinking and activity can be the basis for the tutor's activity.On the one hand, it can be carried out only in a specific situation, and on the other, they are recorded in culture in the form of values and norms. And then the tutor decides concerning the student what criteria and methods of constructing the necessary ratios of objectification and subjectivization of activity in the latter formation process will lead to the "construction" of transitions from objectively presented ways of thinking and activity that exist in a particular cultural environment to 
situationally (individually) meaningful forms. The tutor's activity consists in identifying and highlighting a real activity situation and in translating it (this situation) into an educational one.

\section{The concept of meta-competencies}

Since one of the tasks of the tutor is the development of student's metacog-nitive competencies, it seems reasonable to fix the concept of the latter.

Fixing the concept of "competency" we find ourselves in a fairly formalized space, defined already at the level of standards [9], which describe the results of training in certain educational programs. Competencies there are considered as cer-tain sets of socially demanded knowledge, skills for the implementation of certain types of activities. Usually, in the psychological and pedagogical literature, the con-cepts of "competency" and "competencies" are different. By the first one we mean precisely the qualities of the person, the measure of matching his knowledge, skills, understanding the real level of complexity of the tasks that he is solving. The second one means his zone of responsibility and authority. Competency and competencies are complementary and interdependent. Indeed, without the required level of compe-tence, a person with certain powers will not be able to provide the required level of accomplishment of the tasks, and a person with sufficient competence, but not hav-ing the authority to manifest it, will not be able to fully realize it. However, under-standing this difference, nevertheless, we will use them synonymously, since, firstly, the concrete meaning is always taken out of context, and, secondly, we are more concerned about non-socially determined ways and possibilities of manifestation specific knowledge and methods of activity, and the processes of their formation.

Recently, in the literature on education, the words with the prefix "meta" have often begun to appear: meta-cognition, meta-objectness, meta-competence. The prefix "meta" is Greek, is translated "after, subsequent to, following, through" and usually indicates the level of description of an object or system higher than the previous description, that is, it represents a "description of the description." The sec-ond meaning of the prefix "meta" is going beyond something [10]. Then meta-competencies can be described as integrated complexes of competencies that have systemic quality and are invariant to the subject matter of specific types of activity, including educational, as well as the person's ability to form new competencies and skills depending on the challenges of social reality.

It should be noted that a large number of studies $[11,12,13]$ are devoted to the study of meta-competencies. And, based on their analysis, it can be fixed that meta-competencies are understood as meta- objectness, meta-cognitiveness and meta-creative thinking of graduates of educational, including engineering, programs.

\subsection{Meta-disciplinarity}

Meta-disciplinarity may be defined as a principle that ensures the integration of the education content, as a way of forming theoretical thinking and universal methods of activity that ensure the formation of a holistic picture of the world in the student's mind. And meta-disciplinarity knowledge may be defined as a conscious and meaningful result of a cognitive activity, based on which the students form a holistic picture of the world, characterized by a reflective character, contributing to the awareness and regulation of their life.

Despite the large number of researches devoted to the study of the meta-disciplinarity content of education, it is still difficult to identify and describe certain universal metrics that would make it possible to measure the quality of mastering basic educational programs, that is, to quantify indicators of the formation of meta-disciplinarity skills. The methods, 
observations, expert evaluations and testing are most often described in the studies, which are not only about the conceptual content of the definition, but also about the diagnosis of achieving meta-disciplinarity re-sults $[14,15]$.

\subsection{Meta-cognition}

Meta-cognitive processes are highlighted by J. Flavell, who havedefined them as individual knowledge regarding his cognitive processes and the results of cognitive activity. The fundamental concept of Flavell's metacognition is the concept of "thinking relative to one's thinking". These thoughts may relate to what a person knows (a meta-cognitive knowledge), what he is currently doing, (a metacognitive skill), or what current cognitive or emotional state he has (a metacognitive sensation) [16]. The structure of metacognitive processes includes metacognitive knowledge and metacognitive regulation.

The specificity of metacognitive processes is in the fact that they are simultaneously cognitive and regulatory processes, aimed at obtaining information about their cognitive activity, function in problem situations, and perform the function of conscious internal control over cognitive processes and strategies. The importance of metacognitive processes is that they allow the student to manage cognitive activity and thereby make it more effective. Metacognitive skills can be defined as the skills of students transforming their cognitive activity.

Thus, the student's intellectual development involves not only improving the cognitive mechanisms of information processing, but also the formation of metacognitive mechanisms of intellectual self-regulation. The most important quality of a modern specialist is the ability to choose a strategy of the training, modify it taking into account own intellectual capabilities under the influence of new requirements.

\subsection{Meta-creativity}

Q Creativity in its' most general form is described as an ability of a person to go beyond the stimulus situation, to offer answers that are highly original and non-standard in thinking. A creative solution, as a rule, is based on considering the hidden properties of an object, its original application, a combination of "incompatible" properties, transferring existing rules of behavior to new conditions and new objects, etc.

One of the key qualities laid down in most test methods for determining crea-tivity is the originality of the answer. It describes the statistical rarity of the answer regarding the studied sample.

Then, based on the meaning of the prefix "meta", meta-creativeness can be defined as a certain integral quality of the personality, providing not only the ability of the personality to go beyond the stimulus situation but also the ability to realize how this solution is realized, to choose the most appropriate strategies for it, as well as providing a high level of personality self-referentiality.

\section{Modern practice of tutoring}

An authentic source - research on the problems of tutors, sponsored by practicing tutors themselves is of particular interest in the analysis of the tutoring content and technology in the XX-th century. Palfreyman D., a scientist and tutor at a New College in Oxford, considers tutoring as an indisputable asset of British education and argues that tutor is not a teacher in the usual sense: knowledge transfer is not the field of his activity, the student must find information by himself. The teacher-tutor here acts as a constructive critic, 
helping to understand information, verify it, explore possible ways of working, discard one approach, giving preference to another. D. Pelfreiman concludes his work with the words: "When all efforts were made to make education effective, it is indisputable that there is no substitute for individual tutoring. Their function is not to educate, but to set the student the task of expressing his thoughts logically and reasonably and help him, subjecting his creations to critical analysis and processing. ... "[17].

Another tutor A. Ruan in his study "Free Learning" reveals an interesting "method of questions" as a technology of tutoring: "What can surprise an ideal student is that the tutor only asks questions; it is learning by questions, and it doesn't matter how deep and accurate the student's answers are. The purpose of this meeting is to make the student teach himself, understanding how to get out of the web of questions: "If you think that, then what can you say about ...?" An ideal tutor can resist the temptation to dictate to the student what he needs to write down and learn. He is confident that a young, energetic and intelligent student will teach himself what he needs to know - as long as he is asked the right questions"[18]. A tutor in the modern British university system of higher education acts as a curator who supervises classes (scheduling classes, conducting tutorials, exams, consultations, monitoring academic performance, academic consultations); a teacher who conducts practical (seminar) classes and provides consultations on a specific discipline, organizing and performing students' independent work, structuring knowledge in this area, managing semester and course work, organizing practice; psychologist-analyst who helps in solving problems of a personal nature; facilitator (from the English "facilitate, help"), contributing to the maximum self-expression of the student through psychological support during the training; teacher in distance learning. Such content of tutoring activities involves the following means of its' implementation: group and individual consultations, interviews, tutorials (weekly classes), disputes, electronic correspondence, seminars. The main tool for training, education and the basic functional duty of a tutor is the creation of an individual educational program, which is constantly being refined and adjusted. Changes are made depending on a joint analysis of the student's progress and progress on the path to knowledgemastering. The core concept of such pedagogy is the uniqueness of the human personality, its' purpose (including professional) and the individualization of learning associated with it [19].

\subsection{Tutoring practices in Russian education system}

As it can be seen, Russian educational practices are similar to oneson what the English model of tutorship is based on. It seems that this practice is most widespread at the institute of scientific leadership, including one implemented in the educational activities of school students. So, since 2009, the program "Step into the Future" began to prepare students in the framework of their research studies, where the participants are also involved in research projects led by their mentors in addition to traditional educational activities[20].

Thus, the main goal of tutoring in the Russian education system is the pedagogical support of the development and implementation of an individual educational trajectory based on the principle of individualization, by student.

The space of a modern university is an open cultural and educational environment where many schools, many authorities, many teachers, each of which is an author of his course, are mutually represented.The knowledge and truth are represented in this space as the highest values, and not only and not so much from their broadcast, but much from the creative implementation in the activity. This requires some mediation position that helps the student to navigatein this environment. This position can be taken by a tutor. This becomes especially significant today, when the entire sphere of education gravitates toward 
universality and cultural openness, focusing on the values of the personality and freedom, towards transferring the center of education management to the pole of the student.

Indeed, it has become evident now that the largest increase in tangible assets is provided by people who have the more global capital (in the terminology of Pierre Bourdieu). He writes: "Capital, depending on the area in which it operates, and at the cost of more or less serious transformations, which are the prerequisite for its effective action in this area, can appear in three main forms: economic capital, which is directly converted into money and institutionalized in the form of property rights; cultural capital, which under certain conditions is converted into economic capital and can be institutionalized in the form of educational qualifications; social capital formed by social obligations ("connections")(my emphasis - E. G.), which under certain conditions is converted into economic capital and can be institutionalized, for example, in the form of an aristocratic title "[21]. Often, these people have a double education: technical (or natural), and humanitarian (or socio-economic). Indeed, in the modern job market, such a universal specialist is more in demand, precisely because of the specific features of his mental practices, the universality of his thinking, because they possess the qualities that Professor A. A. Dobryakov denotes as mental, social and functional literacy [22].

It is noteworthy that at the same time the basic paradigm of the educational institution is changing: from the concept of "education for the whole life", the social subject moves on to the idea of "education through life", from a passive object of "correct" pedagogical influences, he turns into an actively acting individual, responsible for his education. Accordingly, not "knowledge packages" in various professional disciplines (of course, we do not dispute the importance of owning them), but rather, "mentally organized principles of intellectual activity" become more popular in the educational service market. This approach will be a continuation of the famous "Russian method of training engineers", for which BMSTU received the gold medal of the World Exhibition in San Francisco in 1878 [23].

\section{Conclusion}

So, as it has been mentioned above, tutoring consisted of three complementary elements:

- tutoring focused on student learning during a certain period of study (social request for knowledgeable specialists);

- occupational guidance (supervision), providing students with study and work, including ones during the holidays (a combination of social and individual);

- moral mentoring, which involves accompanying the student's life at the university in the broadest sense of the word (individual request).

The tutor was included in all these three processes not from an external position, as a specialist, but as an included figure: as a rule, he continued to conduct scientific research, self-education and lived with the student according to the laws of university life, in one value and one way. At the same time, the tutor is personally responsible for the readiness of each of his charges for exams. The same practiceexists in many Russian universities, but it is called differently. Another thing is that often these roles are separated. So, the supervisor is usually responsible for the disciplinary moments of students' learning. The mentor is personally responsible for the quality of the academic preparation of students working under his supervision, and often he also performs the role of a moral mentor.

The tutor's task is to set the path to mastering the material for the student. And if at an English university of the XVII-XVIII centuries the tutor was a figure that accelerated the education process by building the optimal learning path, nowadays the need for a tutor is even more increased due to the need for lifelong learning, since speed of updating and changing of the technologies are increasing all the time. 
If the university is considered as a model of civil society, then a tutor can act for a student not only as a mentor but also as a citizen and as a friend. Thus, a panorama of an initially essentially disparate material existing in the education system (teaching, education and formation of a way of thinking and lifestyle) can be built for a student through the activity of a tutor. And most importantly, this panorama will be associated with the possibilities of its' individual development.

Therefore, it can be recorded that the tutor is a figure accompanying the training of the student, and what is important, as the meaning of the word "accompaniment" implies, the student must be a moving figure himself! Because it is impossible to accompany one who does not go! Thus, the idea of the tutor is the idea of striving for knowledge of the student!

Summarizing, we'llrecord the main points of our research:

1. The situation of our time is similar to the enlightened Middle Agesin many ways, with the only difference - there are more degrees of uncertainty. The student needs a guide.

2. Self-education as a way of life is possible in a free and autonomous space, where freedom and knowledge are recognized as enduring values.

3. Tutor is a middleman between free personalities in the space of education.

4. A tutor is a middleman between the cultural and the individual (the large history of those who know and the individual history of the neophyte), the individual and the corporate.

5. A tutor can be someone who has come the same way, that is, has an experience of self-education, and he passes it on.

6. A tutor connects the processes of learning, self-education and the formation of a lifestyle in the education of his student.

7. University education is universal education, It makes it possible to make knowledge personal, effective. Thus, a place for tutor's activity appears in it, but today the whole world is becoming an educational universe - and the tutor must redefine his place.

Today, on the one hand, Russia is becoming a part of the global community, incorporating the values of civil society into its culture. On the other hand, there is a long tradition of mentoring in our educational system, which is very similar to the tradition of tutoring that was originated in English universities. Perhaps this is the point of growth that will lead to the formation of a new educational paradigm based on humanitarian principles and on an anthropological approach.

\section{References}

1. Oxford Wordpower Dictionary, 3rd edition, p. 767. Oxford University press (2014).

2. N.L. Sokolova, T.Y. Tsibizova, Building a Professional Career in Conditions of Continuous Education, Nauchnyi Dialog 1, pp. $295-299$ (2018). DOI: 10.24224/22271295-2018-1-295-299.

3. A.O. Karpov, Education in Relation to Truth. VoprosyFilosofii 1, pp. 56-66 (2019). DOI: $10.31857 / \mathrm{S} 004287440002581-4$.
4. A.O. Karpov, University 3.0 - Social Mission and Reality, $\begin{array}{llllll}\text { SotsiologicheskieIssledovaniya } & 9, \quad \text { pp. } & 114-124 & \text { (2017). DOI: }\end{array}$ 10.7868/S0132162517060137.

5. M.K. Mamardashvili, Modern European philosophy (XX century), Logos: Philosophical and Literary Journal 2, pp. 109-130 (1991).

6. M.K. Mamardashvili, Modern European philosophy (XX century), Logos: Philosophical and Literary Journal 2. pp. 109-130 (1991). 
7. A.P.Avdeeva , N.G. Bagdasaryan, Y.A. Safonova, Way To Yourself: A Model Of Professional Realization Of Hearing Impaired Students, Advances in Social Science, Education and Humanities Research Proceedings of the 4th In-ternational Conference on Contemporary Education, Social Sciences and Humanities (ICCESSH 2019), pp. 660-664 (2019).

8. E. Gordon, E. Gordon, Centuries of Tutoring, A History of alternative education in America and Western Europe, University Press of America, Inc. (1990).

9. Portal of Federal State Educational Standards of Higher Education URL: http://fgosvo.ru, last accessed 27.12.2019.

10. The Free Dictionary by Farlex.

URL: https://www.thefreedictionary.com/Meta+(prefix), last accessed 27.12.2019.

11. A. Scharnhorst, W. Ebeling, Evolutionary Search Agents in Complex Landscapes - a New Model for the Role of Competence and Meta-competence (EVOLINO and other simulation tools).

URL: http://virtualknowledgestudio.nl/documents/_andreascharnhorst/arxiv_final.pdf last accessed 27.12.2019.

12. J. Erpenbeck, A. Scarnhorst, W. Ebeling, D. Martens, P. Nachtigall, K. North, P. Friedrich, A. Lantz, Metakompetenzen und Kompetenzentwicklung, QUEM-report, SchriftenzurberuflichenWeiterbildung. Heft 95/Teil I., Berlin (2006). URL: https://knaw.academia.edu/AndreaScharnhorst, last accessed 27.12.2019.

13. M. Bogo, E. Katz, C. Regehr, C. Logie, M. Mylopoulos, L. Tufford, Toward Understanding Meta-Competence: An Analysis of Students' Reflection on their Simulated Interviews, Social Work Education: The International Journal, Volume 32, Issue 2, Special Issue: Field Education in Social Work, pages 259-273 (2013). DOI: 10.1080/02615479.2012.738662.

URL: http://www.tandfonline.com/doi/abs/10.1080/02615479.2012.738662\#.VMoGsqv3uCd , last accessed 27.12.2019.

14. A. Scharnhorst, W. Ebeling, Evolutionary Search Agents in Complex Landscapes - a New Model for the Role of Competence and Meta-competence(EVOLINO and other simulation tools). URL: http://virtualknowledgestudio.nl/documents/_andreascharnhorst/arxiv_final.pdf, last accessed 27.12.2019.

15. E. Gavrilina, M. Zakharov, A. Karpenko, E. Smirnova, A. Sokolov, Software system META-3 for quantitative evaluation of student's metacompetencieson the basis of analysis of his or her behavior in social networking services, Askhat, D. (ed) XII International Symposium Intelligent Systems/ M. 103, pp. $432-438$ (2017). DOI: 10.1016/j.procs.2017.01.012.

16. J. Livingston, Metacognition: an Overview. URL: http://gse.buffalo.edu/fas/shuell/cep564/metacog.htm, last accessed 27.12.2019).

17. D. Palfreyman, Higher Education, Liberal Education, Critical-thinking, Academic Discourse, and the Oxford Tutorial as Sacred Cow or Pedagogical Gem, The Oxford Tutorial: «Thanks, you taught me how to think», OxCHEPS, pp. 1-16 (2008). URL: http://oxcheps.new.ox.ac.uk/Publications/Resources/OxCHEPS_OP1_08.pdf, last accessed 27.12.2019).

18. A. Ruan. A Liberal Education: and that includes the Sciences!, The Oxford Tutorial: "Thanks, you taught me how to think", OxCHEPS, pp. 17-20 (2008). URL: http://oxcheps.new.ox.ac.uk/Publications/Resources/OxCHEPS_OP1_08.pdf, last accessed 27.12.2019. 
19. The Oxford Tutorial: 'Thanks, you taught me how to think' Edited by David Palfreyman, Published by OxCHEPS, 2008 (second edition) Oxford Centre for Higher Education Policy Studies. URL: http://oxcheps.new.ox.ac.uk/Publications/Resources/OxCHEPS_OP1_08.pdf, last accessed 27.12.2019.

20. A.O. Karpov, University 3.0 - Social Mission and Reality, $\begin{array}{llllll}\text { SotsiologicheskieIssledovaniya } & 9, & \text { pp. } & 114-124 & \text { (2017). DOI: }\end{array}$ 10.7868/S0132162517060137.

21. P. Bourdieu, ÖkonomischesKapital, kulturellesKapital, sozialesKaputal, in: Kreckel, Reinhard(ed.) SozialeUngleichheiten (Soziale Welt, Sonderheft 2), Güttingen: Otto Schwartz \& Co., pp. 183-198 (1983). Richardson, John (ed.) Handbook of Theory and Research for the Sociology of Education. N.Y., Westport, Conn.: Greenwood Press, 1986. P. 241-258. Economic sociology. Vol. 6. №3. May 2005. P. 60-74. Translation by M.S. Dobryakova. Scientific editing - V.V. Radaev. - access

22. A.A. Dobryakov, Psychological and pedagogical fundamentals of training elite specialists as creative personalities (substantive elements of subject-object pedagogical technology), M..: Logos, p. 363 (2001).

23. E. Gavrilina, Enineering Creativity: An Essay on Epistemological Analysis, Pisano R. (ed), Bridge Between Conceptual Frameworks: Sciences, Society and Technology Studies, vol. 27, pp. 195-205 (2015). DOI: 10.1007/978-94-017-9645-3_11. 